\title{
Allicin Inhibits Proliferation and Invasion in Vitro and in Vivo via SHP-1-Mediated STAT3 Signaling in Cholangiocarcinoma
}

\author{
Huinan Chena,b Biqiang Zhu a,b Lei Zhao ${ }^{a}$ Yang Liu ${ }^{a} \quad$ Fuya Zhao ${ }^{a}$ Jing Feng ${ }^{a}$ \\ Ye Jin ${ }^{\mathrm{a}}$ Jiayu Sun ${ }^{\mathrm{a}}$ Rui Geng ${ }^{\mathrm{a}}$ Yunwei Wei ${ }^{\mathrm{a}}$ \\ ${ }^{a}$ Department of Oncological and Endoscopic Surgery, The First Affiliated Hospital of Harbin Medical \\ University, Harbin, ${ }^{\mathrm{b}}$ Translational Medicine Research and Cooperation Center of Northern China, \\ Harbin, China
}

Key Words

Allicin • Cholangiocarcinoma • Proliferation • Invasion

\begin{abstract}
Background/Aims: Cholangiocarcinoma (CCA) is a malignant tumor that is resistant to chemotherapy, so new therapeutic agents are needed. Allicin which is rapidly converted from allin by allinase, is one of the most biologically active compounds in freshly crushed garlic and has been shown to have strong anti-tumor effects. Our aim was to explore the molecular mechanism by which allicin affects the cell proliferation and invasion of CCA. Methods: Cell viability and apoptosis were measured using the CCK-8 assay, colony formation assay, and flow cytometry. Cell migration and invasion were evaluated by wound healing and Transwell assays, respectively. The expression of several proteins involved in cell apoptosis and invasion were assessed by Western blot. The activation of STAT3 signaling was detected by Western blot and immunofluorescence staining. The involvement of SHP-1 was determined using small interfering RNA (siRNA). Moreover, a nude mouse model of human CCA was established to assess the anti-tumor effects of allicin in vivo. Results: Allicin significantly suppressed CCA cell proliferation by activating the caspase cascade, inducing apoptosis, and reducing the expression of proteins downstream of STAT3, such as B-cell lymphoma 2 (Bcl-2), while upregulating $\mathrm{BCl}$-2-associated $\mathrm{X}$ (Bax) protein. In addition, allicin inhibited the migration, invasion, and epithelial-mesenchymal transition (EMT) of CCA cells. Moreover, the protein expression of MMP-2 and MMP-9 was significantly downregulated in CCA cells treated with allicin compared with CCA cells treated with control. Mechanistic investigations indicated that allicin upregulated SHP-1 expression in CCA, and pervanadate treatment reversed the allicininduced downregulation of STAT3. Moreover, suppression of SHP-1 by siRNA overturned the effect of allicin on the induction of SHP-1 and inhibition of STAT3 activation. Additionally, treatment with allicin attenuated tumor growth in the nude mouse model of CCA. Conclusions: Our findings suggest that allicin suppresses cell proliferation and invasion via STAT3 signaling and may be a potential therapeutic agent for CCA.
\end{abstract}

H. Chen and B.Zhu contributed equally to this work.

\begin{tabular}{ll}
\hline Yunwei Wei & Dept. of Oncological and Endoscopic Surgery, The First Affiliated Hospital of Harbin \\
& Med. Univ. Harbin, Heilongjiang 150001 (China) \\
& E-Mail hydwyw11@hotmail.com
\end{tabular}




\section{Introduction}

Cholangiocarcinoma (CCA) is the second most common hepatic malignancy and is a heavy burden on patients and society; moreover, the overall incidence of CCA has increased progressively worldwide over recent years [1, 2]. For most CCA patients, treatment options are noncurative and mainly involve chemotherapy; a minority of CCA patients are diagnosed with resectable disease, but there is also a high relapse rate among these patients who undergo potentially curative surgery [3]. CCA is generally refractory to most forms of chemotherapy, and the 5-year survival rate ranges from $5 \%$ to $15 \%$ among all CCA patients $[4,5]$. Thus, studies aiming to develop low-toxicity drugs for the prevention and treatment CCA are urgently needed.

Signal transducer and activator of transcription 3 (STAT3) plays a critical role in proliferation, survival, apoptosis, angiogenesis, and metastasis $[6,7]$ upon stimulation by several cytokines and growth factors during tumorigenesis $[8,9]$. STAT3 is a convergent point for a number of oncogenic signaling pathways via phosphorylation at tyrosine residue 705 [10]. Moreover, STAT3 modulates the expression of genes involved in anti-apoptosis (Bcl-2, Bcl-xL, and survivin), proliferation (cyclin D1) [11], and angiogenesis (VEGF) [12]. Recently, studies have reported that STAT3 is constitutively activated in many cancers, including breast cancer [13], ovarian cancer [14], and lung cancer [15]. Inhibition of STAT3 cascade-related protein expression has been shown to induce cell cycle arrest and apoptosis [16]. In CCA, activation of the STAT3 pathway is also vital for cell growth and metastasis [17].

Several studies have indicated that STAT3 activation is negatively regulated by protein tyrosine phosphatases (PTPs) [18]. Src homology region 2 (SH2) domain-containing phosphatase 1 (SHP-1) belongs to a family of non-receptor PTPs and has been identified as a negative regulator of numerous cytokine signaling pathways [19]. Previous studies have shown that SHP-1 tyrosine phosphatase, which negatively targets phosphorylated (p)-STAT3 signaling in a wide variety of tumors, exhibits significant anti-tumor activity by triggering apoptosis and suppressing tumor formation [20-22]. Consequently, the STAT3 pathway may represent a target for therapeutic intervention in CCA. Various STAT3 inhibitors have been shown to inhibit tumor cell growth and metastasis in vitro and in vivo [23, 24].

Natural agents derived from medicinal plants have attracted attention from researchers and clinicians because of their safety, efficacy, and immediate availability, and they are the one of the best sources of drugs and drug leads for novel drug discovery [25]. Natural agents, such as cryptotanshinone [26], emodin [27], and betulinic acid [28], have shown significant efficacy in blocking STAT3 activation. Allicin, an organosulfur compound that can be isolated from freshly crushed garlic, has been shown to possess numerous biological actions, such as anti-inflammation and anti-microbial $[29,30]$. Several studies have also reported that allicin represses cancer growth in vitro, including lung cancer, hepatocellular carcinoma, melanoma, and colorectal adenocarcinoma [31, 32]. However, the function and regulatory mechanism of allicin in CCA proliferation and invasion are still not well understood. On the basis of these findings, we sought to examine the potential actions of allicin on the STAT3 signaling pathway in CCA cells. We found that allicin inhibited the STAT3 cascade by inducing the expression of the protein tyrosine phosphatase SHP-1.

\section{Materials and Methods}

\section{Cells and culture}

Human CCA cell lines (HuCCT-1 and QBC939) were cultured in RPMI-1640 medium supplemented with $10 \%$ fetal bovine serum (Gibco, Carlsbad, CA, USA) and 1\% penicillin-streptomycin solution (SigmaAldrich, St. Louis, MO, USA). All cells were incubated at $37^{\circ} \mathrm{C}$ and $5 \% \mathrm{CO}_{2}$.

\section{Chemicals and reagents}

Allicin (purity $>90 \%$ ) was obtained from Yuanye Biological Technology Co. Ltd. (Shanghai, China) and was dissolved in dimethyl sulfoxide (DMSO) and diluted in RPMI-1640 medium to achieve the desired 


\section{Cellular Physiology Cell Physiol Biochem 2018;47:641-653

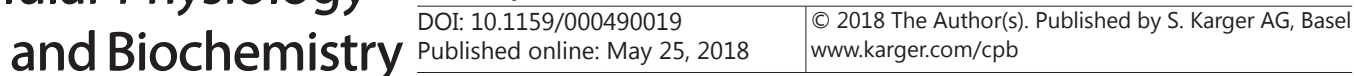 \\ Chen et al.: Allicin Inhibits Cholangiocarcinoma}

concentration for the in vitro experiments. The final concentration of DMSO in the culture medium was maintained at $0.1 \%$.

\section{Cell Counting Kit-8 assay}

Cell proliferation was assessed using a Cell Counting Kit-8 (CCK-8) (Dojindo, Kumamoto, Japan). In brief, CCA cells $\left(3 \times 10^{3}\right.$ cells/well) were seeded into each well of a 96-well plate and cultured for $24 \mathrm{~h}$ in conditioned medium before allicin treatment. The indicated concentrations of drugs were added to the wells, and incubated for 24,48 , or $72 \mathrm{~h}$. Finally, cell viability was measured as the relative optical density (OD) at $450 \mathrm{~nm}$. The percentage of viable cells was calculated using the following formula: cell viability (\%) $=(\mathrm{OD}$ of treated cells $) /(\mathrm{OD}$ of control cells $) \times 100$.

\section{Colony formation assay}

One thousand CCA cells were seeded in 35-mm dishes and allowed to grow overnight. The cells were then exposed to DMSO or different concentrations of allicin. After $24 \mathrm{~h}$, the medium was replaced with normal medium, and the cells were cultured for another 14 days. Then, the cells were washed gently with phosphate-buffered saline (PBS), and the colonies were fixed with 95\% ethanol and stained with $0.1 \%$ crystal violet. The number of colonies ( $>50$ cells) in each group was counted under a microscope.

\section{Cell apoptosis assay}

Cells $\left(2 \times 10^{5}\right.$ cells/well) in 6-well plates were treated with varying concentrations of allicin for $24 \mathrm{~h}$. The cells were collected and washed twice in ice-cold PBS. The cells were incubated with $4 \mu \mathrm{L}$ FITC-Annexin $\mathrm{V}$ and $5 \mu \mathrm{L}$ propidium iodide (PI) at room temperature for $15 \mathrm{~min}$ in the dark. Apoptotic cells were detected using an Annexin V-FITC Kit (BD Pharmingen, Franklin Lakes, NJ, USA) according to the manufacturer's protocol. All samples were analyzed immediately by flow cytometry.

\section{Cell migration assay (wound healing assay)}

The cells were seeded into 6-well plates in the appropriate culture medium. A sterile 100 - $\mu \mathrm{L}$ pipette tip was subsequently used to create wounds. The plates were washed with PBS to remove cell debris, and the cells were incubated in complete growth medium containing either $0,5,10$, or $20 \mu \mathrm{M}$ allicin for $24 \mathrm{~h}$. Cell migration was observed with an inverted microscope at different time points $(0$ and $24 \mathrm{~h})$ post-allicin administration. The number of cells that migrated into the denuded area in each of 6 random fields was measured and quantified with computer-assisted microscopy (Original magnification $\times 40$ ).

\section{Transwell migration assay}

Cell invasion was quantified using Transwell cell culture chambers. The cells were treated with either $0,5,10$, or $20 \mu \mathrm{M}$ allicin for $24 \mathrm{~h}$ and then harvested. A total of $2 \times 10^{4}$ cells in serum-free RPMI- 1640 medium were added to the upper chamber of the Transwell membranes, which were precoated with Matrigel and RPMI-1640 medium; $600 \mu \mathrm{L}$ RPMI-1640 medium containing 10\% fetal bovine serum was added to the lower chamber as a chemo-attractant. The cells were then incubated for $24 \mathrm{~h}$ at $37^{\circ} \mathrm{C}$. The cells that adhered to the upper surface of the membrane were removed using cotton swabs, and the cells that had migrated to the underside of the membrane were washed twice with PBS, fixed with methanol, and then stained with $0.1 \%$ crystal violet for $30 \mathrm{~min}$. The migrated cells on the underside of the membrane were counted under a microscope at $100 \times$ magnification. Cell counts in six random fields of each Transwell membrane were analyzed and averaged.

\section{Immunofluorescence analysis}

HuCCT- 1 cells were seeded in confocal dishes $\left(1 \times 10^{4}\right.$ cells/well $)$ with different concentrations of allicin. The samples were fixed in $4 \%$ paraformaldehyde and permeabilized with $0.1 \%$ Triton X-100 in PBS. Subsequently, the cells were incubated with the indicated primary antibodies overnight at $4^{\circ} \mathrm{C}$. After washing 3 times with PBS, the cells were probed with a red fluorescence-labeled secondary antibody for $30 \mathrm{~min}$ in the dark. The nuclei were stained with 4',6-diamidino-2-phenylindole. Images were taken using fluorescence microscopy (Original magnification $\times 400$ ). Each immunofluorescence assay was repeated 3 times.

\section{KARGER}




\section{Cellular Physiology Cell Physiol Biochem 2018;47:641-653

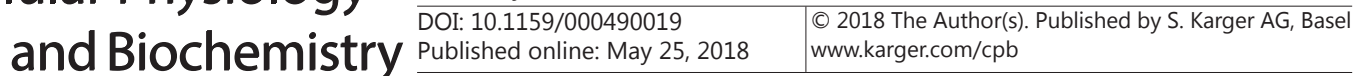 \\ Chen et al.: Allicin Inhibits Cholangiocarcinoma}

\section{Small interfering RNA and plasmid transfection}

For RNA interference, the negative control (NC) small interfering RNA (siRNA) and the SHP-1 siRNA were purchased from GenePharma (Suzhou, China). The sequences targeting SHP-1 were as follows: 5'-GGAGAAAGGCCGGAACAAA-3' (siRNA-1) and 5'-CCUCUUUCCGGCCUUGUUU-3' (siRNA-2).

For plasmid overexpression, STAT3C plasmid was obtained from Liaoning Baihao Biological Technology Co. Ltd. (Shenyang, China). These plasmids or siRNAs were subsequently transfected into the cells using the Lipofectamine 2000 reagent (Invitrogen, Carlsbad, CA, USA).

Nuclear protein isolation and Western blot analysis

Nuclear protein was extracted using a Nucleus and Cytoplasmic Protein Extraction Kit (Beyotime, Shanghai, China) according to the manufacturer's instructions. Equal amounts of total or nuclear protein (20-120 $\mu \mathrm{g})$ were resolved by 8-12\% SDS-PAGE and transferred to a PVDF membrane (Millipore, Bedford, MA, USA). After blocking, the membrane was incubated with specific primary and secondary antibodies. The primary antibodies were as follows: anti-STAT3, anti-cleaved caspase-3, anti-cleaved caspase-9, antiBcl-2, anti-Bcl-2-associated X protein (Bax), anti-E-cadherin, anti-vimentin, anti-MMP-2, anti-MMP-9, antip-STAT3 (Tyr705), anti-SHP-1, anti-SHP-2, anti-TC-PTP, anti-histone H3, and anti- $\beta$-actin (Cell Signaling Technology, Danvers, MA, USA). The targeted protein band was visualized via chemiluminescence Western blot detection reagent (ECL kit). The intensity of each blot was quantified using ImageJ software after normalization to the corresponding loading control.

\section{Mouse xenograft model}

All experiments were performed in accordance with national guidelines and as recommended by the institute's animal ethics committee. Five-week-old male athymic nude mice were purchased from Beijing Vital River Laboratory Animal Technology (Beijing, China). Approximately $2 \times 10^{7}$ HuCCT- 1 cells were injected into the right flank of the nude mice. When the tumors grew to approximately $100 \mathrm{~mm}^{3}$, the mice were divided randomly into vehicle or allicin treatment groups ( $\mathrm{n}=6$ per group). For the treatment group, allicin at $10 \mathrm{mg} / \mathrm{kg}$ and $20 \mathrm{mg} / \mathrm{kg}$ doses was administered by intraperitoneal injection (i.p.) to mice daily for 4 weeks; mice in the control group were administered vehicle. Body weight and tumor volume were recorded every 2 days. Tumor length (L) and width (W) were measured with a Vernier caliper, and tumor volume (TV) was calculated by the following formula: TV $=\left(\mathrm{L} \times \mathrm{W}^{2}\right) / 2$. The mice in both the treatment and control groups were sacrificed, and the tumors were collected for further analysis.

\section{Statistical analysis}

All data are expressed as the mean \pm standard deviation of at least 3 independent experiments for each group. Statistical significance was determined using Student's t-test (for comparisons of two groups) or one-way analysis of variance (for multiple group comparisons). A $P$-value of less than 0.05 was considered statistically significant. All statistical analyses were carried out using the SPSS 21.0 software (SPSS, Inc. Chicago, IL, USA).

\section{Results}

Allicin inhibits CCA cell proliferation and colony formation in vitro

Allicin is an organosulfur compound derived from garlic [33]; the chemical structure of allicin is shown in Fig. 1A. To explore the anti-proliferative effect of allicin, we performed the CCK8 cell proliferation assay using a panel of CCA cells, including HuCCT-1 and QBC939 cells. The cells were treated with varying concentrations of allicin $(0,5,10,20$, or $40 \mu \mathrm{M})$ for 24, 48, or $72 \mathrm{~h}$. Allicin effectively inhibited HuCCT-1 and QBC939 cell proliferation in a dose- and time-dependent manner (Fig. 1B). To determine the long-term growth inhibitory effects of allicin, colony formation assays were performed. We analyzed the clonogenicity of different CCA cell lines after treatment with different concentrations of allicin. As shown in Fig. 1C, allicin treatment resulted in a marked decrease in the number of CCA cell colonies. Our data indicated that CCA cell proliferation was inhibited by allicin, which was consistent with prior results. These findings showed that allicin may function as a tumor suppressor in human CCA. 


\section{Cellular Physiology Cell Physiol Biochem 2018;47:641-653 \begin{tabular}{l|l|l} 
DOI: 10.1159/000490019 & O 2018 The Author(s). Published by S. Karger AG, Basel \\
www.karger.com/cpb
\end{tabular} \\ Chen et al.: Allicin Inhibits Cholangiocarcinoma}

\section{Allicin induces CCA cell apoptosis}

In addition, we examined the pro-apoptotic propensity of allicin. Annexin V/PI staining was used to investigate whether allicin can induce apoptosis in CCA cells. Flow cytometry analysis showed that a large percentage of HuCCT-1 cells underwent apoptosis after exposure to allicin (Fig. 2A). We further investigated the underlying molecular mechanisms by Western blot. Our data indicated that caspases, including cleaved caspase- 3 and cleaved caspase-9, which are critical apoptotic proteins, were induced in CCA cells by allicin in a dose-dependent manner. Conversely, the expression level of Bcl-2, which is closely related to tumor cell growth, survival, and apoptosis, was significantly reduced by allicin treatment, whereas Bax levels were significantly increased (Fig. 2B). Collectively, these results showed that allicin inhibits CCA cell growth and induces apoptosis.

Allicin inhibits the migration, invasion, and epithelial-mesenchymal transition of CCA cells Cell migration and invasion are significant processes during tumor formation and growth. To determine whether allicin inhibits CCA cell migration and invasion, we cultured HuCCT-1 cells with varying doses of allicin. We examined cell invasion capacity with a Matrigel-coated

Fig. 1. Effect of allicin on the proliferation of CCA cells. (A) Chemical structure of allicin. (B) CCA cells (HuCCT-1 and QBC939) were treated with increasing concentrations of allicin for 24,48 and $72 \mathrm{~h}$, and a CCK-8 assay was performed. Data are expressed as the mean \pm $\mathrm{SD} ; \mathrm{n}=3$ for each group. ${ }^{*} \mathrm{P}<0.05$; $* * \mathrm{P}<0.01$ versus the control group. (C) CCA cells were seeded into 35 $\mathrm{mm}$ plates and treated with different concentrations of allicin for two weeks. The surviving colony numbers were counted manually. Data are expressed as the mean \pm $\mathrm{SD} ; \mathrm{n}=3$ for each group. ${ }^{*} \mathrm{P}<0.05$; ${ }^{* *} \mathrm{P}<0.01 ; * * * \mathrm{P}<0.001$ versus the control group.

Fig. 2. Allicin induces apoptosis of CCA cells. (A) HuCCT-1 cells were treated with allicin at the indicated doses for $24 \mathrm{~h}$. Apoptotic cells were labelled with Annexin V and PI and were analysed by flow cytometry. Data are expressed as the mean \pm $\mathrm{SD} ; \mathrm{n}=3$ for each group. ${ }^{* *} \mathrm{P}<0.01$ versus the control group. (B) A Western blot assay was used to detect the levels of apoptosis-related proteins after allicin exposure. The bands were then quantified by Image J software. Data are expressed as the mean $\pm \mathrm{SD} ; \mathrm{n}=3$ for each group. ${ }^{*} \mathrm{P}<0.05$; ${ }^{* *} \mathrm{P}<0.01$ versus the control group.
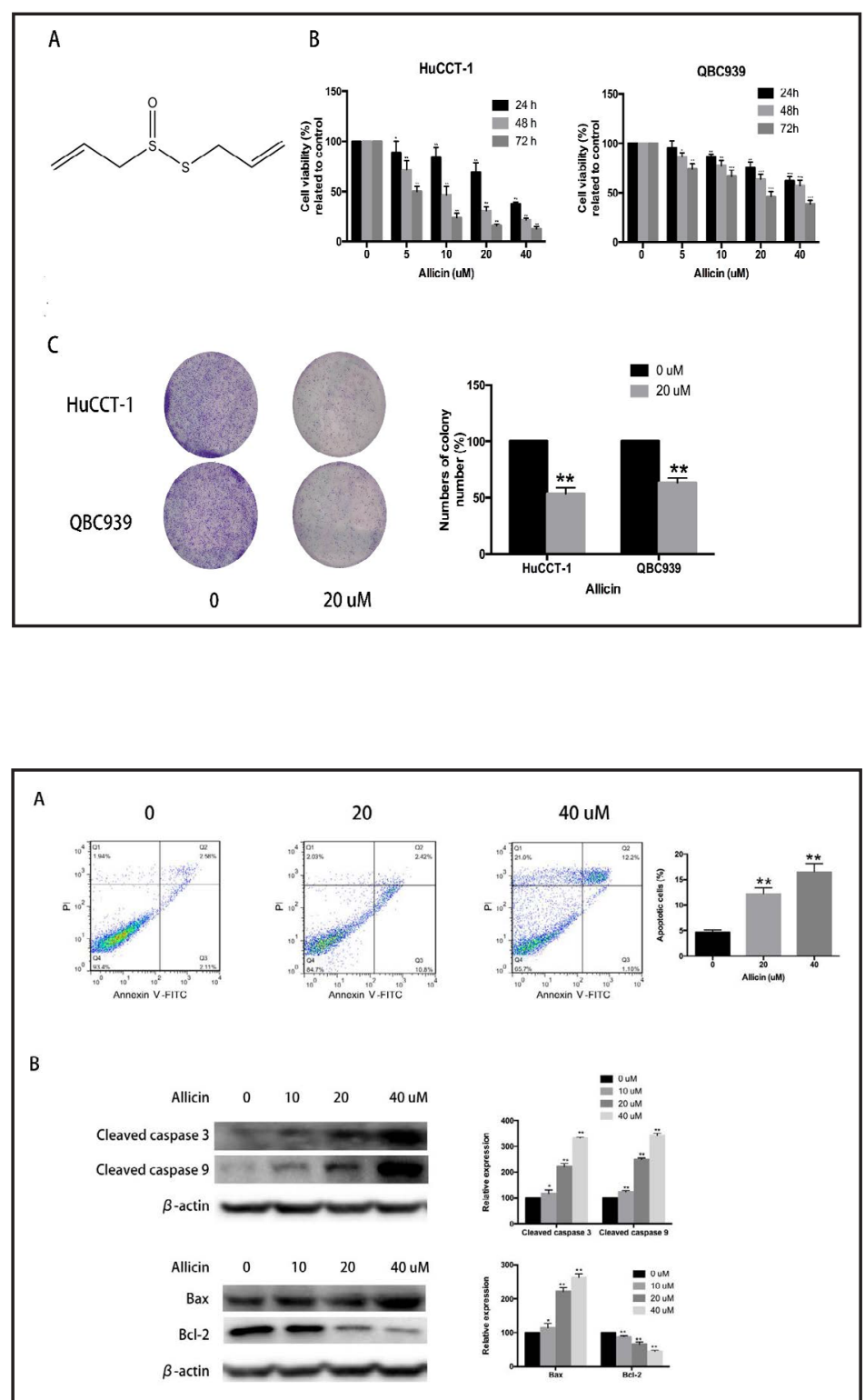
filter. CCA cell invasion was markedly blocked by allicin treatment (Fig. 3A). As shown in Fig. 3B, allicin effectively decreased HuCCT-1 cell migration in wound healing assays in a dosedependent manner. Epithelial-mesenchymal transition (EMT) is considered to be a critical mechanism regulating the initial steps of metastatic progression. To investigate the effect of allicin on CCA, we examined the expression of EMT-associated markers (E-cadherin, MMP-9, MMP-2, and vimentin). We found that allicin could significantly downregulate the expression of MMP-9, MMP-2, and vimentin and upregulate the epithelial cell marker E-cadherin (Fig. 3C). These results suggest that allicin has migration and invasion inhibitory effects in vitro.

\section{Allicin inhibits STAT3 signaling in CCA}

To assess the effect of allicin on STAT3 activation and nuclear translocation, we first identified the effect of allicin on STAT3 phosphorylation by Western blot analysis and immunofluorescence staining assays. After treatment with different concentrations of allicin for different lengths of time, the protein levels of STAT3 and p-STAT3 (Tyr705) in CCA cell lines were detected by Western blot analysis. Allicin clearly abolished STAT3 phosphorylation at Tyr705 without affecting the level of total STAT3 in HuCCT-1 cells in a dose- (Fig. 4A) and time-dependent manner (Fig. 4B). Furthermore, after treatment with allicin for $2 \mathrm{~h}$, STAT3 translocation was detected by immunofluorescence staining in HuCCT-1 cells. As shown in Fig. 4C, nuclear translocation of STAT3 was attenuated by allicin treatment. These data demonstrate that allicin minimizes the phosphorylation of STAT3 at Tyr705 and thereby its nuclear translocation in CCA cells. Western blot analysis also confirmed that nuclear STAT3 expression was reduced by allicin, but the total level of STAT3 expression in cell lysates was not changed (Fig. 4D). These results indicate that allicin inhibits the translocation of STAT3 from the cytoplasm to the nucleus by suppressing its phosphorylation.

\section{Overexpression of STAT3 reverses the anti-tumor effects of allicin}

Due to the importance of STAT3 in CCA cell proliferation and invasion, HuCCT-1 cells were transfected with an empty vector or STAT3C plasmid [34]. The growth of HuCCT-1 cells was inhibited by allicin in a dose-dependent manner, which was partially reversed by STAT3C overexpression (Fig. 5A), but was not affected after transfection with the empty vector. Our results indicated that the inhibitory effects of allicin on CCA cell proliferation are dependent on the suppression of STAT3 activation. Conversely, we investigated the effects on

Fig. 3. Allicin inhibits migration and invasion and reverses the EMT phenotype of CCA cells. (A) Invasion assay. HuCCT-1 cells were resuspended in serum-free medium and seeded into the upper chamber of Transwell inserts precoated with Matrigel. Complete medium containing different concentrations of allicin were added to the bottom well. After $24 \mathrm{~h}$ of incubation, images were obtained $(\times 100)$,

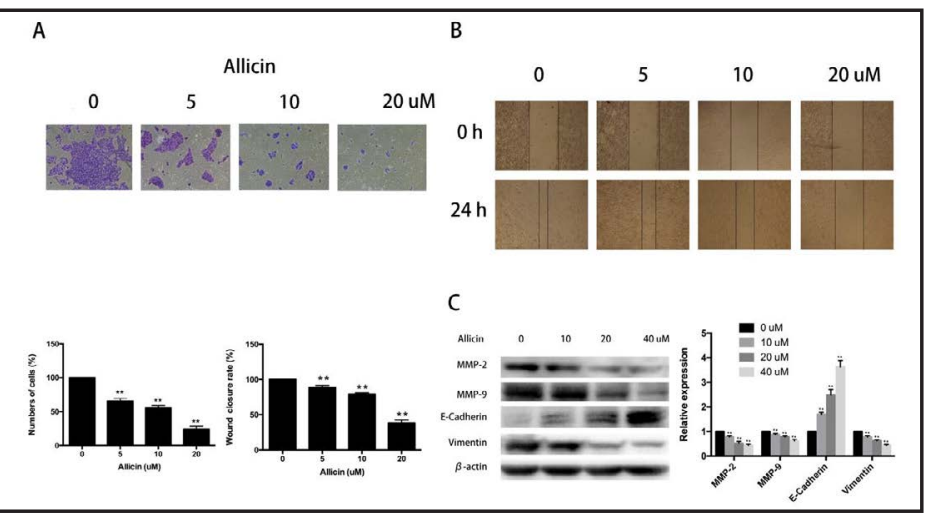
and cell invasion was quantified

manually. Data are expressed as the mean $\pm \mathrm{SD} ; \mathrm{n}=3$ for each group. ${ }^{* *} \mathrm{P}<0.01$ versus the control group. (B) Wound-healing migration assay. HuCCT-1 cells were seeded into six-well plates and allowed to grow to full confluence. Cells were scratched to generate a wound and were then exposed to different concentrations of allicin. Images were acquired after 0 and $24 \mathrm{~h}(\times 40)$. Cell migration was quantified manually. Data are expressed as the mean $\pm \mathrm{SD} ; \mathrm{n}=3$ for each group. ${ }^{* *} \mathrm{P}<0.01$ versus the control group. (C) HuCCT- 1 cells were incubated with increasing doses of allicin. The expression of EMT-related markers was then determined by Western blot. Data are expressed as the mean $\pm \mathrm{SD} ; \mathrm{n}=3$ for each group. ${ }^{* *} \mathrm{P}<0.01$ versus the control group. 
allicin-mediated cell proliferation and invasion after transfection with the STAT3C plasmid. As shown in Fig. 5B, the expression levels of several related proteins, such as cleaved caspase- 3 and cleaved caspase-9, were decreased, while MMP-2 and MMP-9 were increased after STAT3C overexpression. A previous study reported that STAT3 may directly mediate apoptosis and EMT in cancer progression [35]. We next elucidated the effect of p-STAT3, a key upstream regulator that influences downstream protein expression, including the proteins above, which have important roles in STAT3-mediated apoptosis and EMT. After transfection with STAT3C, HuCCT-1 cells were treated with different doses of allicin for $24 \mathrm{~h}$, and we found that the expression levels of cleaved caspase-3, cleaved caspase-9, and E-cadherin

Fig. 4. Allicin inhibits STAT3 activity in CCA. (A) HuCCT-1 cells were exposed to the indicated concentrations of allicin for $24 \mathrm{~h}$. The expression of proteins was analysed by Western blot with the indicated antibodies. Data are expressed as the mean $\pm S D$; $n=3$ for each group. $* * \mathrm{P}<0.01$ versus the control group. (B) HuCCT-1 cells were treated with $20 \mu \mathrm{M}$ allicin for the indicated times, which was followed by Western blot with the indicated antibodies. Data are expressed as the mean \pm S.D; $n=3$ for each group. $* * \mathrm{P}<0.01$ versus the control group. (C) HuCCT-1 cells were treated with allicin $(20 \mu \mathrm{M})$ for $2 \mathrm{~h}$. Representative immunofluorescence im-

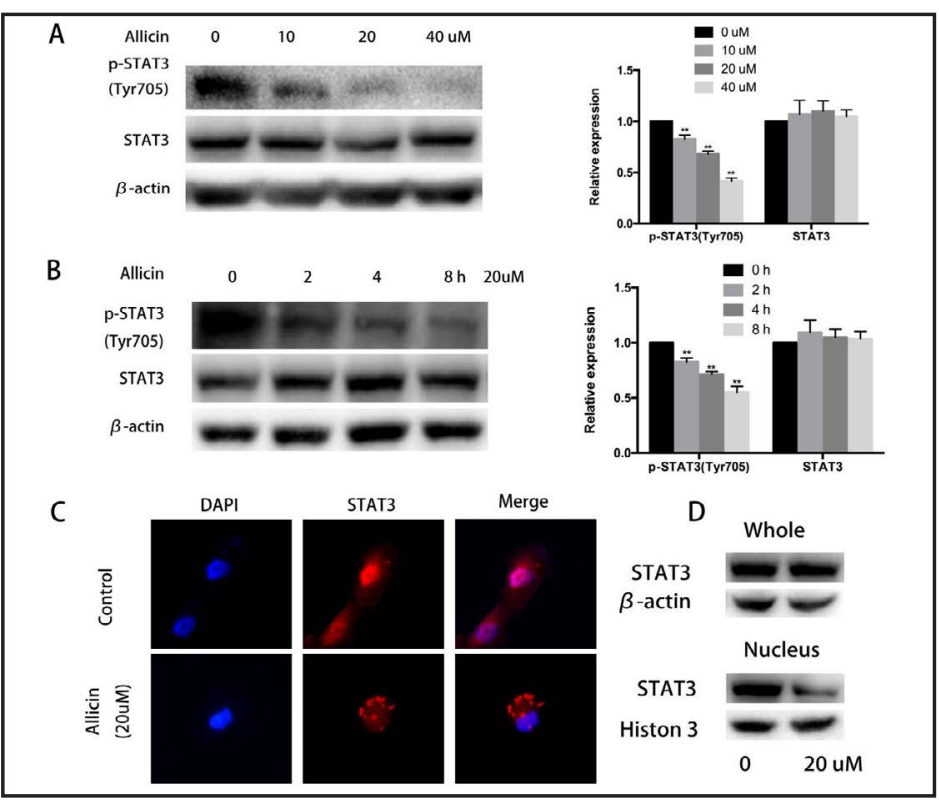
ages $(\times 400)$ revealed the nuclear levels of STAT3 (red), $n=3$ for each group. (D) HuCCT-1 cells were treated with allicin for $24 \mathrm{~h}$, and the cytoplasmic and nuclear extractions were assessed to detect the level of STAT3. Data are expressed as the mean $\pm S D ; n=3$ for each group.

Fig. 5. Overexpression of STAT3 reverses the anti-tumour effects of allicin. (A) CCA cells were transfected with empty vector or the STAT3C plasmid for $24 \mathrm{~h}$ and then treated with allicin at the indicated concentrations for $24 \mathrm{~h}$. Cell proliferation was measured by CCK8 assay. Data are expressed as a percentage versus control (100\%). Data are expressed as mean $\pm \mathrm{SD}$; $\mathrm{n}=3$ for each group. ${ }^{* *} \mathrm{P}<0.01$ versus empty vector (EV) control; ${ }^{\# \#} \mathrm{P}<0.01$. (B) Cell lysates from EVor STAT3C-transfected CCA cells

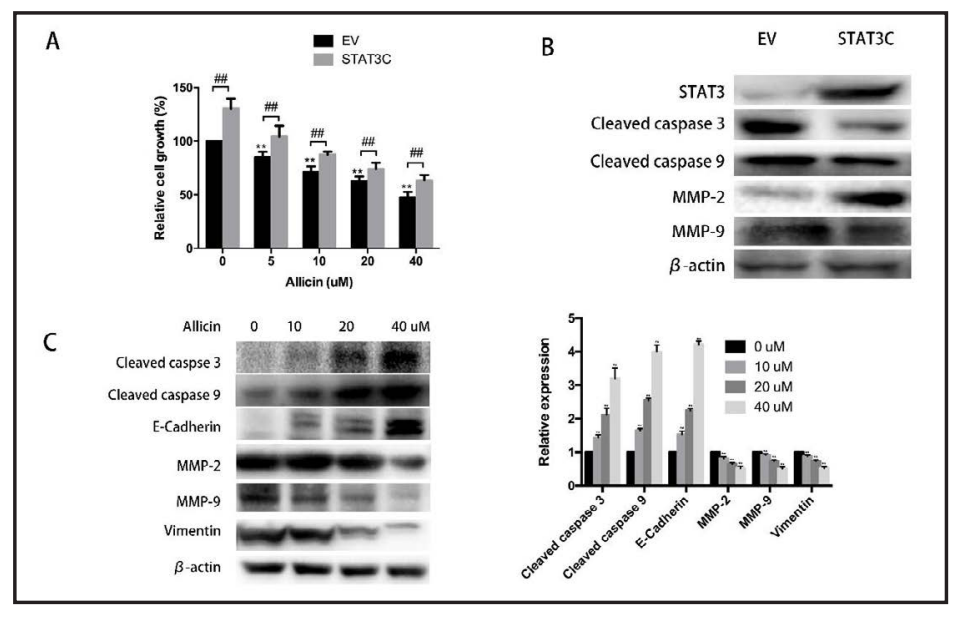
were analysed by Western blot.

Data are expressed as the mean \pm SD; $n=3$ for each group. (C) CCA cells were treated with the indicated concentration of allicin for $24 \mathrm{~h}$. The expression of proteins was analysed by Western blot with the indicated antibodies. Data are expressed as the mean $\pm \mathrm{SD} ; \mathrm{n}=3$ for each group. ${ }^{* *} \mathrm{P}<0.01$ versus the control group.

\section{KARGER}




\section{Cellular Physiology Cell Physiol Biochem 2018;47:641-653 \begin{tabular}{l|l} 
and Biochemistry Published & $\begin{array}{l}\text { DOI 10.115/000490019 } 2018 \text { The Author(s). Published by S. Karger AG, Basel } \\
\text { www.karger.com/cpb }\end{array}$
\end{tabular} \\ Chen et al.: Allicin Inhibits Cholangiocarcinoma}

were increased, whereas MMP-2, MMP-9, and vimentin expression was decreased in a dosedependent manner (Fig. 5C).

Inhibitory effect of allicin on p-STAT3 (Tyr705) is mediated by SHP-1

Numerous PTPs have been reported to be negative regulatory factors of STAT3 (Tyr705) phosphorylation [36]. Therefore, we wondered whether the allicin-induced inhibition of STAT3 could be due to the activation of PTPs. Treatment of HuCCT-1 cells with the broadacting tyrosine phosphatase inhibitor sodium pervanadate for $2 \mathrm{~h}$ reversed the $10 \mu \mathrm{M}$ allicin-induced suppression of STAT3 activation in a dose-dependent manner (Fig. 6A). This result suggests that PTPs are involved in the inhibition of STAT3 (Tyr705) phosphorylation by allicin. To identify which PTP is involved in this process, SHP-1, SHP-2, and TC-PTP protein expression was analyzed in HuCCT-1 cells. However, there were no notable changes in the expression of TC-PTP or SHP-2 protein, but treatment with allicin led to the increased expression of SHP-1 protein (Fig. 6B). We next explored the influence of PTP gene silencing. HuCCT-1 cells were transfected with SHP-1 or negative control siRNA for $48 \mathrm{~h}$ and then treated with $10 \mu \mathrm{M}$ allicin for $2 \mathrm{~h}$. As shown in Fig. 6C, knockdown of SHP-1 by siRNA dramatically reversed the effect of allicin on STAT3 phosphorylation at Tyr705. Our results demonstrated that the increase in SHP-1 expression induced by allicin may be associated with the downregulation of STAT3 activation.

\section{Allicin inhibits tumor growth in nude mice bearing CCA xenografts}

To assess whether the biological effect of allicin on CCA is clinically relevant, we detected its effect on tumor growth in vivo using subcutaneous CCA-implanted nude mice.

Fig. 6. Inhibitory effect of allicin on p-STAT3 is mediated by SHP-1. (A) Pervanadate reverses the inhibitory effect of allicin on STAT3 activation. HuCCT-1 cells were treated with pervanadate at the indicated concentration for $2 \mathrm{~h}$ and with an additional $10 \mu \mathrm{M}$ allicin for 2 h. STAT3 and p-STAT3 Tyr705 protein expression was analysed by Western blot. The expression of proteins was analysed by Western blot with the indicated antibodies. Data are expressed as the mean \pm $\mathrm{SD} ; \mathrm{n}=3$ for each group. ${ }^{*} \mathrm{P}<0.05$; ${ }^{* *} \mathrm{P}<0.01$ versus allicin $0 \mu \mathrm{M}$ group. (B) HuCCT-1 cells were treated with the indicated concentrations of allicin for 24 h. SHP-1, TC-PTP, SHP- 2 and $\beta$-actin protein expression was analysed by Western blot. Data are expressed as the mean \pm $\mathrm{SD} ; \mathrm{n}=3$ for each group. ${ }^{*} \mathrm{P}<0.05$; $* * \mathrm{P}<0.01$ versus the control group. (C) HuCCT-1 cells were transfected with siRNA against specific phosphatases including SHP-1 or negative control (NC) for $48 \mathrm{~h}$ and were then treated with allicin at the indicated concentration for $2 \mathrm{~h}$. This was followed by Western blot analysis with the indicated phosphatase antibodies. The expression of p-STAT3 Tyr705 relative to STAT3 was quantified by densitometry. Data are expressed as the mean $\pm \mathrm{SD} ; \mathrm{n}=3$ for each group. ${ }^{* *} \mathrm{P}<0.01$.

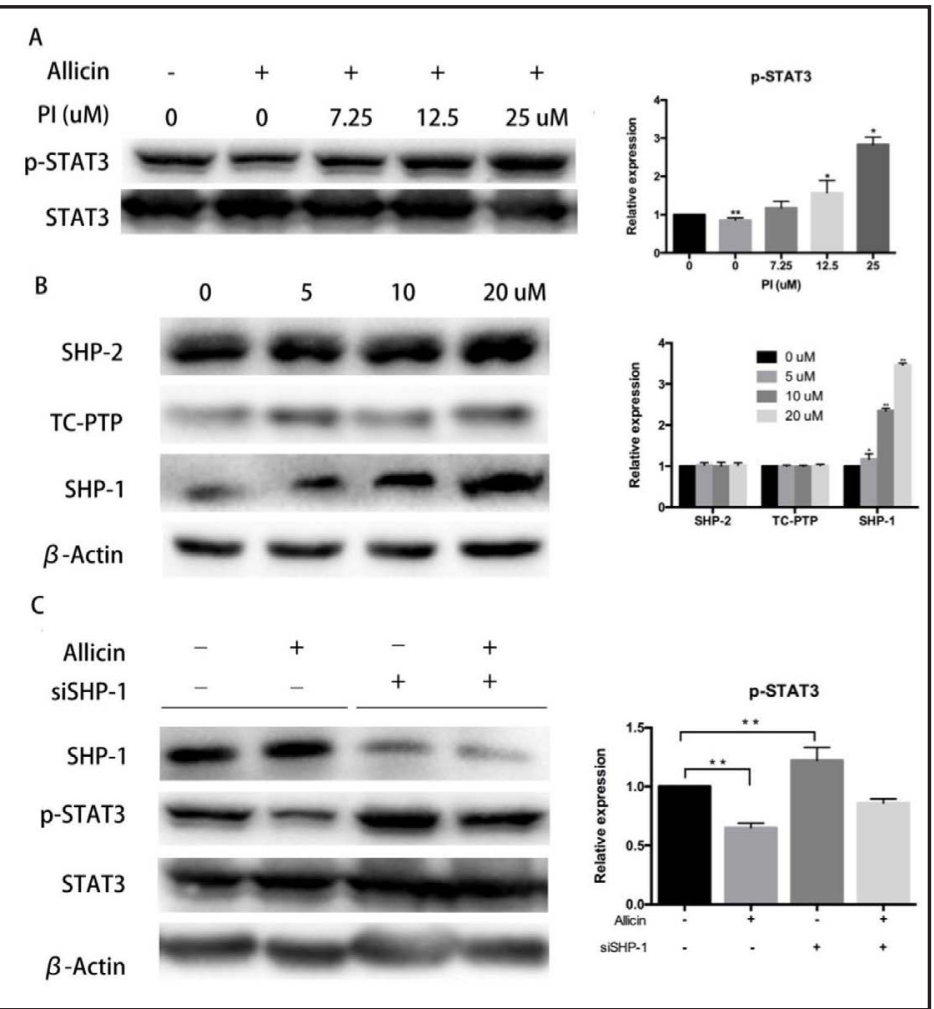


HuCCT-1 CCA xenografts were established and allowed to grow to approximately $100 \mathrm{~mm}^{3}$, after which allicin was administered i.p. daily for 4 weeks. Discernible differences in tumor growth among the allicin-treated and control tumors were observed. As shown in Fig. 7A, our data indicated a great discrepancy in tumor volume between the allicin-treated groups and the control group. In line with this, tumor weight was significantly reduced after allicin administration compared with the vehicle-treated controls (Fig. 7B). No apparent toxicityrelated events were observed in the allicin-treated animals, and no significant changes in body weight were observed after treatment with allicin (Fig. 7C). Furthermore, we found that allicin increased p-STAT3 (Tyr705) levels and downregulated the expression of cleaved caspase-9 and vimentin (Fig. 7D). These results again showed that allicin enhances apoptosis and inhibits EMT. These data implied that the growth inhibitory effect of allicin correlates with the suppression of STAT3 signaling; moreover, few side effects were observed for the therapeutic dose used in mice. These results strongly support the hypothesis that allicin exerts anti-tumor effects on CCA.

\section{Discussion}

Conventional therapies for CCA may induce drug resistance and are also associated with a variety of side effects [37]; therefore, novel therapies for CCA are urgently needed. Accumulating evidence has shown that natural or dietary agents may be novel therapies for cancer [35, 38]. Here, our present study highlights the anti-tumor effects of a natural product, allicin, which mainly involves the suppression of SHP-1-mediated STAT3 signaling. Our findings that allicin could inhibit proliferation, migration, and invasion suggest that it is a potent anti-tumor compound that may be a promising pharmacotherapy for the prevention and treatment of CCA.

Several epidemiological and preclinical findings support the view that an increased dietary intake of garlic can reduce the risks of many human diseases, such as different types of cancer [39]. In our study, we chose to investigate the effects of allicin, the most abundant

Fig. 7. Allicin attenuates cell growth while activating cell apoptosis and invasion in vivo. (A) Images of representative tumours excised from the animals of each group are presented to show the sizes of the resulting tumours, $n=6$ for each group. (B) Statistical analysis of tumour weight. Data are expressed as the mean $\pm S D ; n=6$ for each group. ${ }^{* *} \mathrm{P}<0.01$ versus model control group. (C) The weight of each mouse was measured every 2 days. (D) Protein expression was analysed by Western blot. Data are expressed as the mean $\pm S D$; $n=6$ for each group. ${ }^{* *} \mathrm{P}<0.01$ versus model control group.

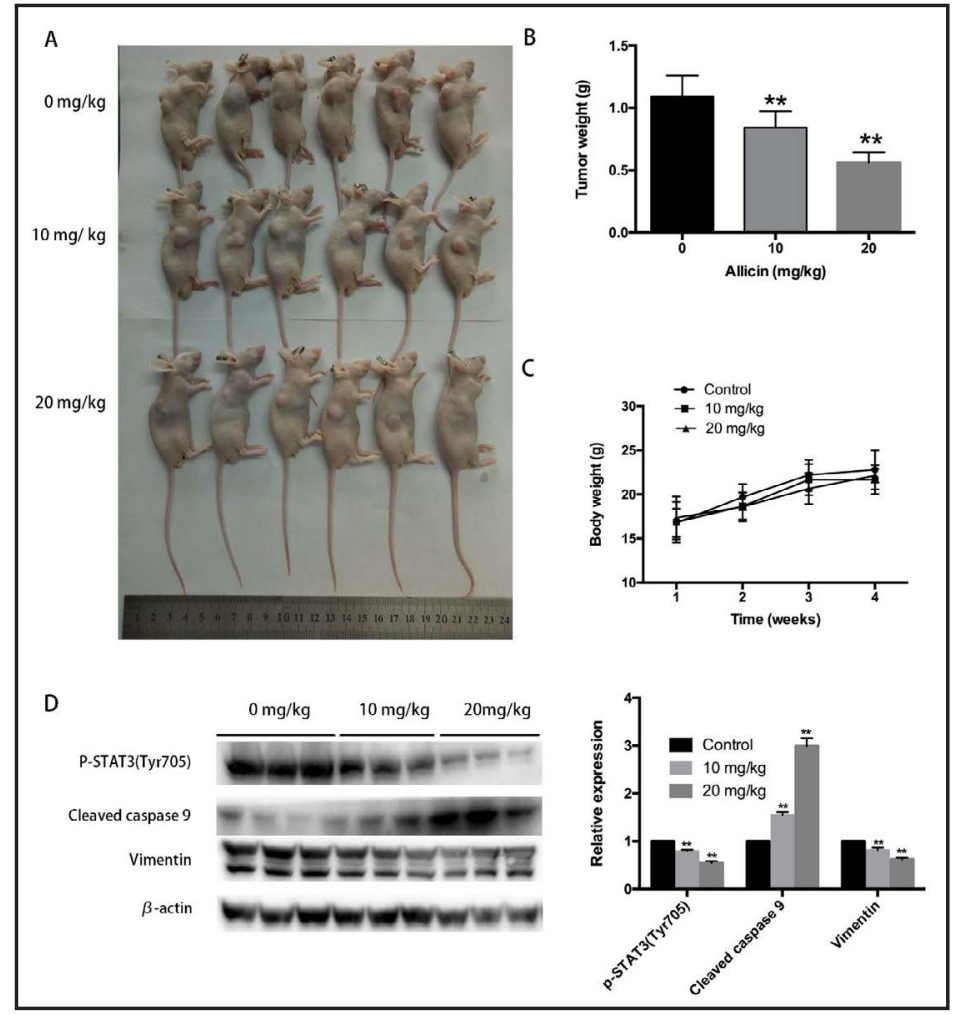


organosulfur compound in freshly crushed garlic [40]. Allicin has been shown to have different health-promoting effects in several studies; for example, allicin can be used as a cardioprotective agent and is associated with increased endothelial function [41]. Also, there are data comprehensively showing that different mechanisms mediate its anti-tumor effects in various types of tumor cells [42, 43]. In our study, we focused on how allicin inhibits CCA cell proliferation and invasion through STAT3 signaling. STAT3 is a key transcription factor involved in inflammation [44], angiogenesis [45], migration, and proliferation [46]. It is considered as an oncogene due to its tumor-promoting effect. Targeting STAT3 in tumors via various methods has shown beneficial effects in both preclinical and clinical studies [47]. Allicin-induced cell apoptosis is a complicated process that is mediated through various pathways and is regulated by many apoptosis-related proteins [43, 48]. Moreover, previous studies have documented that STAT3 is able to affect tumor initiation and promotion [49]. Our data provide evidence that allicin significantly increases the expression of pro-apoptotic proteins, such as cleaved caspase-3/9, to induce apoptosis. Conversely, allicin suppresses the expression of several STAT3-regulated genes, including the anti-apoptotic gene product $\mathrm{Bcl}-2$. Constitutive activation of STAT3 can affect oncogenesis by protecting cancer cells from apoptosis, indicating that the suppression of STAT3 activation by allicin may facilitate the induction of apoptosis.

Tumor migration and invasion is a rather sophisticated process and is often correlated with EMT. During the process of EMT, carcinoma cells lose their epithelial characteristics, including polarity and cell-cell adhesions, and acquire a mesenchymal phenotype to obtain an invasive capacity [50]. Several studies have indicated that the expression of MMP-2 and MMP-9 is associated with EMT, and vimentin is often used as a marker of mesenchymally derived cells or cells undergoing EMT during both normal development and metastatic progression $[51,52]$. However, the STAT3 signaling pathway has been shown to be involved in tumor EMT [53]. Our results showed that allicin significantly inhibits the migration and invasion capacity of CCA cells and reduces the expression of MMP-2/9 and vimentin, but increases E-cadherin protein levels in a dose-dependent manner. Reversing CCA cell EMT behavior may partly explain the allicin-induced reduction of tumor migration and invasion. These results support the hypothesis that allicin serves as a novel STAT3 inhibitor that antagonizes EMT and may thereby prevent CCA metastasis.

In this study, we found for the first time that allicin suppresses the activation and nuclear translocation of STAT3 via a PTP. SHP-1 is a non-receptor PTP that is mainly restricted to hematopoietic cells and epithelial cells. The SHP-1 tyrosine phosphatase has been shown to play a role in the negative regulation of cell signaling [54]. Notably, SHP-1 has tumorsuppressive potential due to its negative regulation of STAT3 oncogenic signaling during tumor progression [55]. Our results showed that allicin stimulates the upregulation of SHP-1 and that inhibition of SHP-1 expression by siRNA abolishes the inhibitory effects of allicin on STAT3 activation, indicating that SHP-1 is involved in the allicin-mediated inhibition of STAT3 signaling in CCA cells. Therefore, SHP-1 is likely the phosphatase responsible for allicininduced STAT3 dephosphorylation. However, SHP-1 contains two SH2 domains: a catalytic PTP domain and a C-terminal tail [56, 57]. How allicin increases SHP-1 activity remains to be elucidated in a future study. Many drugs have been shown to have anti-tumor effects independent of the p-JAKs Tyk2 and Src, which are the upstream kinases of STAT3 signaling $[58,59]$. However, we did not examine whether tumor indexes were changed following the phosphorylation of these protein kinases. In a future study, we will evaluate the upstream kinases of STAT3 signaling.

Whether these in vitro effects of allicin were relevant in vivo was also investigated. Remarkably, our results showed that allicin robustly inhibited tumor growth in tumorbearing mice during the course of the experiment compared with control mice. We also found that allicin downregulated p-STAT3 (Tyr705) and vimentin levels in tumor tissue and increased the levels of cleaved caspase- 9 in the treated group compared to the control group, therefore mirroring our data from cultured cells. These results showed that allicin may provide significant clinical benefits in the treatment of CCA.

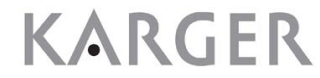


Our study suggests that allicin may inhibit CCA proliferation and invasion by inhibiting SHP-1-mediated STAT3 signaling. However, in a future study, we should investigate whether allicin induces its anti-tumor activity by impairing/activating other signaling pathways. Further studies are also required to explore thoroughly the molecular mechanism of allicin, which can help us better understand its effect on CCA. In addition, it will be essential to investigate the efficacy of allicin against other types of cancer and whether STAT3 inhibitors may have beneficial therapeutic effects on other types of cancer.

\section{Acknowledgements}

This work was supported by the Translational Medicine Research and Cooperation Center of Northern China.

\section{Disclosure Statement}

The authors declare to have no commercial or financial conflict of interests.

\section{References}

1 Saha SK, Zhu AX, Fuchs CS, Brooks GA: Forty-Year Trends in Cholangiocarcinoma Incidence in the U.S.: Intrahepatic Disease on the Rise. Oncologist 2016;21:594-599.

- Khan SA, Taylor-Robinson SD, Toledano MB, Beck A, Elliott P, Thomas HC: Changing international trends in mortality rates for liver, biliary and pancreatic tumours. J Hepatol 2002;37:806-813.

- Wang Y, Li J, Xia Y, Gong R, Wang K, Yan Z, Wan X, Liu G, Wu D, Shi L, Lau W, Wu M, Shen F: Prognostic nomogram for intrahepatic cholangiocarcinoma after partial hepatectomy. J Clin Oncol 2013;31:11881195.

4 DeOliveira ML, Cunningham SC, Cameron JL, Kamangar F, Winter JM, Lillemoe KD, Choti MA, Yeo CJ, Schulick RD: Cholangiocarcinoma: thirty-one-year experience with 564 patients at a single institution. Ann Surg 2007;245:755-762.

-5 Everhart JE, Ruhl CE: Burden of digestive diseases in the United States Part III: Liver, biliary tract, and pancreas. Gastroenterology 2009;136:1134-1144.

6 Lee JH, Kim C, Kim SH, Sethi G, Ahn KS: Farnesol inhibits tumor growth and enhances the anticancer effects of bortezomib in multiple myeloma xenograft mouse model through the modulation of STAT3 signaling pathway. Cancer Lett 2015;360:280-293.

7 Ahn KS, Sethi G, Sung B, Goel A, Ralhan R, Aggarwal BB: Guggulsterone, a farnesoid X receptor antagonist, inhibits constitutive and inducible STAT3 activation through induction of a protein tyrosine phosphatase SHP-1. Cancer Res 2008;68:4406-4415.

8 Zhang J, Li Z, Liu L, Wang Q, Li S, Chen D, Hu Z, Yu T, Ding J, Li J, Yao M, Huang S, Zhao Y, He X: Long noncoding RNA TSLNC8 is a tumor suppressor that inactivates the interleukin-6/STAT3 signaling pathway. Hepatology DOI: 10.1002/hep.29405.

-9 Deb A, Zamanian-Daryoush M, Xu Z, Kadereit S, Williams BR: Protein kinase PKR is required for plateletderived growth factor signaling of c-fos gene expression via Erks and Stat3. EMBO J 2001;20:2487-2496.

10 Schneller D, Machat G, Sousek A, Proell V, van Zijl F, Zulehner G, Huber H, Mair M, Muellner MK, Nijman SM, Eferl R, Moriggl R, Mikulits W: p19(ARF) /p14(ARF) controls oncogenic functions of signal transducer and activator of transcription 3 in hepatocellular carcinoma. Hepatology 2011;54:164-172.

11 Hu X, Ma J, Vikash V, Li J, Wu D, Liu Y, Zhang J, Dong W: Thymoquinone Augments Cisplatin-Induced Apoptosis on Esophageal Carcinoma Through Mitigating the Activation of JAK2/STAT3 Pathway. Dig Dis Sci 2018;63:126-134.

12 Ji Y, Wang Z, Li Z, Li K, Le X, Zhang T: Angiotensin II induces angiogenic factors production partly via AT1/ JAK2/STAT3/SOCS3 signaling pathway in MHCC97H cells. Cell Physiol Biochem 2012;29:863-874.

13 Du YE, Tu G, Yang G, Li G, Yang D, Lang L, Xi L, Sun K, Chen Y, Shu K, Liao H, Liu M, Hou Y: MiR-205/YAP1 in Activated Fibroblasts of Breast Tumor Promotes VEGF-independent Angiogenesis through STAT3 Signaling. Theranostics 2017;7:3972-3988.

14 Jia ZH, Jia Y, Guo FJ, Chen J, Zhang XW, Cui MH: Phosphorylation of STAT3 at Tyr705 regulates MMP-9 production in epithelial ovarian cancer. PLoS One 2017;12:e0183622.

15 Xu G, Cai J, Wang L, Jiang L, Huang J, Hu R, Ding F: MicroRNA-30e-5p suppresses non-small cell lung cancer tumorigenesis by regulating USP22-mediated Sirt1/JAK/STAT3 signaling. Exp Cell Res 2018;362:268-278. 


\section{Cellular Physiology Cell Physiol Biochem 2018;47:641-653 \begin{tabular}{l|l} 
and Biochemistry Published online: May 25, 2018 & $\begin{array}{l}\text { (c) } 2018 \text { The Author(s). Published by S. Karger AG, Basel } \\
\text { www.karger.com/cpb }\end{array}$
\end{tabular}

16 Banerjee K, Resat H: Constitutive activation of STAT3 in breast cancer cells: A review. Int J Cancer 2016;138:2570-2578.

17 Zheng T, Hong X, Wang J, Pei T, Liang Y, Yin D, Song R, Song X, Lu Z, Qi S, Liu J, Sun B, Xie C, Pan S, Li Y, Luo X, Li S, Fang X, Bhatta N, Jiang H, Liu L: Gankyrin promotes tumor growth and metastasis through activation of IL-6/STAT3 signaling in human cholangiocarcinoma. Hepatology 2014;59:935-946.

18 Vidal OM, Stec W, Bausek N, Smythe E, Zeidler MP: Negative regulation of Drosophila JAK-STAT signalling by endocytic trafficking. J Cell Sci 2010;123:3457-3466.

-19 Liu CY, Su JC, Ni MH, Tseng LM, Chu PY, Wang DS, Tai WT, Kao YP, Hung MH, Shiau CW, Chen KF: Obatoclax analog SC-2001 inhibits STAT3 phosphorylation through enhancing SHP-1 expression and induces apoptosis in human breast cancer cells. Breast Cancer Res Treat 2014;146:71-84.

20 Tai WT, Chu PY, Shiau CW, Chen YL, Li YS, Hung MH, Chen LJ, Chen PL, Su JC, Lin PY, Yu HC, Chen KF: STAT3 mediates regorafenib-induced apoptosis in hepatocellular carcinoma. Clin Cancer Res 2014;20:5768-5776.

21 Su JC, Tseng PH, Hsu CY, Tai WT, Huang JW, Ko CH, Lin MW, Liu CY, Chen KF, Shiau CW: RFX1-dependent activation of SHP-1 induces autophagy by a novel obatoclax derivative in hepatocellular carcinoma cells. Oncotarget 2014;5:4909-4919.

22 Song S, Su Z, Xu H, Niu M, Chen X, Min H, Zhang B, Sun G, Xie S, Wang H, Gao Q: Luteolin selectively kills STAT3 highly activated gastric cancer cells through enhancing the binding of STAT3 to SHP-1. Cell Death Dis 2017;8:e2612.

23 Guo S, Luo W, Liu L, Pang X, Zhu H, Liu A, Lu J, Ma DL, Leung CH, Wang Y, Chen X: Isocryptotanshinone, a STAT3 inhibitor, induces apoptosis and pro-death autophagy in A549 lung cancer cells. J Drug Target 2016;24:934-942.

24 Wong AL, Soo RA, Tan DS, Lee SC, Lim JS, Marban PC, Kong LR, Lee YJ, Wang LZ, Thuya WL, Soong R, Yee MQ, Chin TM, Cordero MT, Asuncion BR, Pang B, Pervaiz S, Hirpara JL, Sinha A, Xu WW, Yuasa M, Tsunoda T, Motoyama M, Yamauchi T, Goh BC: Phase I and biomarker study of OPB-51602, a novel signal transducer and activator of transcription (STAT) 3 inhibitor, in patients with refractory solid malignancies. Ann Oncol 2015;26:998-1005.

-25 Thatte U, Bagadey S, Dahanukar S: Modulation of programmed cell death by medicinal plants. Cell Mol Biol (Noisy-le-grand) 2000;46:199-214.

26 Xia C, Bai X, Hou X, Gou X, Wang Y, Zeng H, Huang M, Jin J: Cryptotanshinone Reverses Cisplatin Resistance of Human Lung Carcinoma A549 Cells through Down-Regulating Nrf2 Pathway. Cell Physiol Biochem 2015;37:816-824.

27 Subramaniam A, Shanmugam MK, Ong TH, Li F, Perumal E, Chen L, Vali S, Abbasi T, Kapoor S, Ahn KS, Kumar AP, Hui KM, Sethi G: Emodin inhibits growth and induces apoptosis in an orthotopic hepatocellular carcinoma model by blocking activation of STAT3. Br J Pharmacol 2013;170:807-821.

28 Pandey MK, Sung B, Aggarwal BB: Betulinic acid suppresses STAT3 activation pathway through induction of protein tyrosine phosphatase SHP-1 in human multiple myeloma cells. Int J Cancer 2010;127:282-292.

29 Mikaili P, Maadirad S, Moloudizargari M, Aghajanshakeri S, Sarahroodi S: Therapeutic uses and pharmacological properties of garlic, shallot, and their biologically active compounds. Iran J Basic Med Sci 2013;16:1031-1048.

30 Kyung KH: Antimicrobial properties of allium species. Curr Opin Biotechnol 2012;23:142-147.

-31 Tsubura A, Lai YC, Kuwata M, Uehara N, Yoshizawa K: Anticancer effects of garlic and garlic-derived compounds for breast cancer control. Anticancer Agents Med Chem 2011;11:249-253.

-32 Rajput S, Mandal M: Antitumor promoting potential of selected phytochemicals derived from spices: a review. Eur J Cancer Prev 2012;21:205-215.

33 Block E: The chemistry of garlic and onions. Sci Am 1985;252:114-119.

-34 Bromberg JF, Wrzeszczynska MH, Devgan G, Zhao Y, Pestell RG, Albanese C, Darnell JE, Jr.: Stat3 as an oncogene. Cell 1999;98:295-303.

-35 Zhang T, Li S, Li J, Yin F, Hua Y, Wang Z, Lin B, Wang H, Zou D, Zhou Z, Xu J, Yi C, Cai Z: Natural product pectolinarigenin inhibits osteosarcoma growth and metastasis via SHP-1-mediated STAT3 signaling inhibition. Cell Death Dis 2016;7:e2421.

-36 Masciocchi D, Gelain A, Villa S, Meneghetti F, Barlocco D: Signal transducer and activator of transcription 3 (STAT3): a promising target for anticancer therapy. Future Med Chem 2011;3:567-597.

37 Tyson GL, El-Serag HB: Risk factors for cholangiocarcinoma. Hepatology 2011;54:173-184.

38 Lan H, Hong W, Fan P, Qian D, Zhu J, Bai B: Quercetin Inhibits Cell Migration and Invasion in Human Osteosarcoma Cells. Cell Physiol Biochem 2017;43:553-567.

-39 Nicastro HL, Ross SA, Milner JA: Garlic and onions: their cancer prevention properties. Cancer Prev Res (Phila) 2015;8:181-189.

40 Majewski M: Allium sativum: facts and myths regarding human health. Rocz Panstw Zakl Hig 2014;65:1-8. 


\section{Cellular Physiology Cell Physiol Biochem 2018;47:641-653 \begin{tabular}{l|l|l} 
DOI: 10.1159/000490019 & O 2018 The Author(s). Published by S. Karger AG, Basel \\
www.karger.com/cpb
\end{tabular} \\ Chen et al.: Allicin Inhibits Cholangiocarcinoma}

41 Zhang M, Pan H, Xu Y, Wang X, Qiu Z, Jiang L:Allicin Decreases Lipopolysaccharide-induced Oxidative Stress and Inflammation in Human Umbilical Vein Endothelial Cells through Supression of Mitochondrial Dysfunction and Activation of Nrf2. Cell Physiol Biochem 2017;41:2255-2267.

-42 Souid S, Najjaa H, Riahi-Chebbi I, Haoues M, Neffati M, Arnault I, Auger J, Karoui H, Essafi M, EssafiBenkhadir K: Allium Roseum L. Extract Exerts Potent Suppressive Activities on Chronic Myeloid Leukemia K562 Cell Viability Through the Inhibition of BCR-ABL, PI3K/Akt, and ERK1/2 Pathways and the Abrogation of VEGF Secretion. Nutr Cancer 2017;69:117-130.

-43 Zou X, Liang J, Sun J, Hu X, Lei L, Wu D, Liu L: Allicin sensitizes hepatocellular cancer cells to anti-tumor activity of 5-fluorouracil through ROS-mediated mitochondrial pathway. J Pharmacol Sci 2016;131:233240.

44 Wong WY, Lee MM, Chan BD, Ma VW, Zhang W, Yip TT, Wong WT, Tai WC: Gynostemma pentaphyllum saponins attenuate inflammation in vitro and in vivo by inhibition of NF-kappaB and STAT3 signaling. Oncotarget 2017;8:87401-87414.

45 Yang M, Wang L, Wang X, Wang X, Yang Z, Li J: IL-6 Promotes FSH-Induced VEGF Expression Through JAK/ STAT3 Signaling Pathway in Bovine Granulosa Cells. Cell Physiol Biochem 2017;44:293-302.

46 Cao Y, Zhao D, Li P, Wang L, Qiao B, Qin X, Li L, Wang Y: MicroRNA-181a-5p Impedes IL-17-Induced Nonsmall Cell Lung Cancer Proliferation and Migration through Targeting VCAM-1 Cell Physiol Biochem 2017;42:346-356.

47 Hong D, Kurzrock R, Kim Y, Woessner R, Younes A, Nemunaitis J, Fowler N, Zhou T, Schmidt J, Jo M, Lee SJ, Yamashita M, Hughes SG, Fayad L, Piha-Paul S, Nadella MV, Mohseni M, Lawson D, Reimer C, Blakey DC, Xiao X, Hsu J, Revenko A, Monia BP, MacLeod AR: AZD9150, a next-generation antisense oligonucleotide inhibitor of STAT3 with early evidence of clinical activity in lymphoma and lung cancer. Sci Transl Med 2015;7:314ra185.

48 Luo R, Fang D, Hang H, Tang Z: The Mechanism in Gastric Cancer Chemoprevention by Allicin. Anticancer Agents Med Chem 2016;16:802-809.

49 Ernst M, Putoczki TL: Stat3: linking inflammation to (gastrointestinal) tumourigenesis. Clin Exp Pharmacol Physiol 2012;39:711-718.

50 Yang J, Weinberg RA: Epithelial-mesenchymal transition: at the crossroads of development and tumor metastasis. Dev Cell 2008;14:818-829.

-51 Saentaweesuk W, Araki N, Vaeteewoottacharn K, Silsirivanit A, Seubwai W, Talabnin C, Muisuk K, Sripa B, Wongkham S, Okada S, Wongkham C: Activation of Vimentin is Critical to Promote a Metastatic Potential of Cholangiocarcinoma Cells. Oncol Res 2017

\$52 Kidoikhammouan S, Seubwai W, Tantapotinan N, Silsirivanit A, Wongkham S, Sawanyawisuth K, Wongkham C: TNP-470, a methionine aminopeptidase-2 inhibitor, inhibits cell proliferation, migration and invasion of human cholangiocarcinoma cells in vitro. Asian Pac J Cancer Prev 2012;13 Suppl:155-160.

53 Das R, Gregory PA, Fernandes RC, Denis I, Wang Q, Townley SL, Zhao SG, Hanson AR, Pickering MA, Armstrong HK, Lokman NA, Ebrahimie E, Davicioni E, Jenkins RB, Karnes RJ, Ross AE, Den RB, Klein EA, Chi KN, Ramshaw HS, Williams ED, Zoubeidi A, Goodall GJ, Feng FY, Butler LM, Tilley WD, Selth LA: MicroRNA-194 Promotes Prostate Cancer Metastasis by Inhibiting SOCS2. Cancer Res 2017;77:1021-1034.

54 Lopez-Ruiz P, Rodriguez-Ubreva J, Cariaga AE, Cortes MA, Colas B: SHP-1 in cell-cycle regulation. Anticancer Agents Med Chem 2011;11:89-98.

55 Fan LC, Shiau CW, Tai WT, Hung MH, Chu PY, Hsieh FS, Lin H, Yu HC, Chen KF: SHP-1 is a negative regulator of epithelial-mesenchymal transition in hepatocellular carcinoma. Oncogene 2015;34:5252-5263.

-56 Yang J, Liang X, Niu T, Meng W, Zhao Z, Zhou GW: Crystal structure of the catalytic domain of proteintyrosine phosphatase SHP-1. J Biol Chem 1998;273:28199-28207.

57 Wang W, Liu L, Song X, Mo Y, Komma C, Bellamy HD, Zhao ZJ, Zhou GW: Crystal structure of human protein tyrosine phosphatase SHP-1 in the open conformation. J Cell Biochem 2011;112:2062-2071.

58 Hilliard TS, Miklossy G, Chock C, Yue P, Williams P, Turkson J: 15alpha-methoxypuupehenol Induces Antitumor Effects In vitro and In vivo against Human Glioblastoma and Breast Cancer Models. Mol Cancer Ther 2017;16:601-613.

59 Nam S, Wen W, Schroeder A, Herrmann A, Yu H, Cheng X, Merz KH, Eisenbrand G, Li H, Yuan YC, Jove R: Dual inhibition of Janus and Src family kinases by novel indirubin derivative blocks constitutively-activated Stat3 signaling associated with apoptosis of human pancreatic cancer cells. Mol Oncol 2013;7:369-378. 